\title{
A IMPORTÂNCIA DA TEORIA DOS CUSTOS DO DIREITO PARA O ESTUDO DO ACESSO À JUSTIÇA NOS TRIBUNAIS JUDICIAIS BRASILEIROS
}

\author{
THE IMPORTANCE OF THE THEORY OF THE COSTS OF THE RIGHT TO THE \\ STUDY OF ACCESS TO JUSTICE IN THE BRAZILIAN JUDICIAL COURTS
}

\section{RODRIGO ALVARES CARNEIRO 1}

RESUMO: Este artigo busca fazer uma abordagem sobre o acesso à justiça frente às dificuldades orçamentárias existentes para a proteção desse direito. Para tanto, foi realizada uma pesquisa eminentemente bibliográfica de estudiosos do acesso à justiça e da teoria dos custos do direito. Foram utilizados, também, dados oficiais sobre a estrutura e as demandas do judiciário brasileiro. Ao fim, demonstrou-se a importância de como a consciência do debate público em torno do orçamento pode trazer uma visão privilegiada acerca das escolhas disjuntivas necessárias para assegurar direitos referentes ao acesso à justiça.

PALAVRAS CHAVES: Acesso à Justiça. Teoria dos custos do Direito. Poder Judiciário brasileiro.

ABSTRACT: This article aims to approach access to justice in face of the budgetary difficulties that exist for the protection of this right. For that, an eminently bibliographical research of scholars of access to justice and of the theory of the costs of rights was carried out. Official data on the structure and demands of the Brazilian judiciary were also used. Lastly, it was demonstrated the importance of how the awareness of the public debate around the budget can bring a privileged vision about the trade-offs necessary to assure rights to access to justice.

KEYWORDS: Access to justice. Theory of costs of rights. Brazilian Judicial system.

1 Possui graduação em Direito pela Universidade do Estado da Bahia (2014), Especialização em Direito Previdenciário e cursa mestrado em Direitos Fundamentais e Justiça na Universidade Federal da Bahia. Atualmente é conciliador - Tribunal de Justiça do Estado da Bahia e Advogado. 


\section{INTRODUÇÃO}

$\mathrm{O}$ acesso à justiça é um direito fundamental que exige, para a sua concretização, diversas intervenções do Estado. A necessidade de um aparato estatal que esteja compatível com a demanda pelo acesso à justiça traz algumas dificuldades de natureza orçamentária como, por exemplo, ter profissionais suficientes e qualificados para julgar e diligenciar os processos, a organização e manutenção de Defensorias Públicas e do Ministério Público, além da criação e manutenção de estrutura física e de material para substanciar as atividades dos servidores, entre outros. Por isso, a discussão sobre o acesso à justiça em face da questão orçamentária estatal se mostra relevante para entendermos alguns entraves para a efetivação de tal direito fundamental.

Dentre as diversas ações possíveis do Estado, com vista a assegurar o acesso à justiça, talvez a mais basilar seja a de criar e manter uma estrutura para o Poder Judiciário. Por isso, é preciso que os órgãos que o compõem sejam capazes de possibilitar ao cidadão um acesso apto a resolver com eficiência as demandas trazidas cotidianamente pelos jurisdicionados. " $E$ que o exercício da função jurisdicional, como é elementar, exige estrutura suficiente, funcionários suficientes, mas, principalmente, juízes suficientes para resolver os processos pendentes" (SOUZA, 2009, p. 29).

Ocorre que, se por um lado, certo é que o acesso à justiça não pode ser confundido tão somente com o acesso ao Poder Judiciário, por outro, não se pode, também, subestimar o papel deste Poder para a promoção do desse direito. Por isso, problemas na estrutura física e de recursos humanos nos órgãos responsáveis pelo Poder Judiciário tendem a refletir diretamente na promoção do acesso à justiça aos cidadãos.

Neste sentido, Paulo Cesar Bezerra (2008, p. 199) lembra que os recursos humanos inerentes ao Poder Judiciário constituem, em verdade, sua parte mais significativa, pois "sem pessoas por trás deles, os cargos não são nada, as instituições são vazias. Sem homens para movimentá-lo, estabelecê-lo, cumpri-lo, produzi-lo, interpretá-lo, aplicá-lo, o direito é uma abstração".

Não obstante a isso, o que se percebe é que atualmente o Poder Judiciário brasileiro não vem conseguindo lidar adequadamente com a quantidade de processos que chegam a cada 


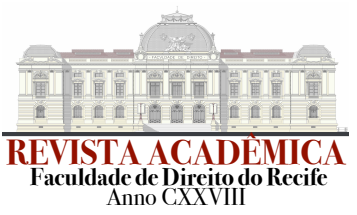

ano; e, sequer, diminuir o número acumulado de demandas, que já somavam 79,7 milhões no ano de 2016, e cujo crescimento anual de 3,6\%, vem aumentando o estoque em 2,7 milhões somente em 2016 (BRASIL, 2017a, p. 65). No mesmo período, curiosamente, a população brasileira cresceu apenas 0,8\% segundo o IBGE (BRASIL, 2017b). Ou seja, há um crescimento mais de quatro vezes maior de processos do que de pessoas no Brasil.

Em razão dessa realidade, foi preciso que o problema do acesso à justiça extrapolasse o âmbito do Poder Judiciário e se tornasse pauta também dos demais poderes do Estado, tornado possível somar esforços em busca de soluções para o problema. Desta forma, a tentativa de concretização desse direito fundamental do cidadão, que é o de poder demandar judicialmente e de obter uma ordem jurídica justa, passou a se tornar preocupação dos três poderes da República brasileira.

Por esta razão, o presente estudo visa traçar paralelos teóricos entre o acesso à justiça e a escassez de recurso, valendo-se da teoria dos custos do direito, a fim de possibilitar uma nova perspectiva que possa servir de interesse aos pesquisadores do tema e trazer uma visão crítica sobre como as limitações orçamentárias podem afetar a concretização do direito ao acesso à justiça.

Dessa forma, emerge a seguinte questão a ser respondida no presente trabalho: em que medida a teoria dos custos do Direito pode ajudar a entender as dificuldades de concretização do acesso à justiça no Brasil?

Para responder tal indagação, no primeiro capítulo do desenvolvimento será apresentado um estudo sobre o acesso à justiça, buscando criar subsídios teóricos sobre o tema. O segundo capítulo, por sua vez, tratará da tensão existente da relação entre escassez de recurso e direito. Por fim, o terceiro se dedicará a traçar um paralelo entre a teoria referente ao acesso à justiça e a teoria dos custos do direito, bem como abordará acerca das consequências teóricas que tal entrelaçamento revela.

Cumpre esclarecer, de logo, que serão excluídas de apreciação do presente trabalho as questões gerenciais do orçamento e das despesas do Poder Judiciário. Tal opção é mais bem explicada em razão de uma escolha de recorte para o trabalho do que por um juízo de 'desvalor' acerca dessas questões. Sucede que, embora se considere relevante pensar sobre como o Poder Judiciário tem despendido os valores que recebe, escolheu-se trabalhar aqui 


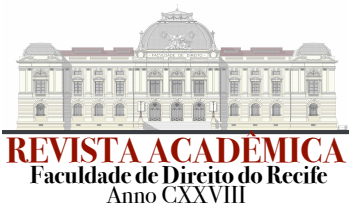

com aspectos do orçamento mais ligados às receitas - o quanto se recebe - do que com as despesas - o que se faz com o que se recebe. O objetivo do presente, portanto, é menos pretensioso, embora não carente de importância, vez que busca tão somente mostrar a relevância que o estudo dos custos do direito pode ter nas pesquisas referentes ao tema do acesso à justiça no Brasil.

Assim sendo, o estudo pretendido será desenvolvido através da pesquisa bibliográfica, com recurso à doutrina específica sobre o acesso à justiça e a teoria dos custos do direito, corroboradas por suas consequentes reflexões constitucionais e processuais. Do mesmo modo, teremos uma abordagem estatística relevante, em razão da necessidade de utilização de investigação sobre os obstáculos do acesso à justiça e as inferências decorrentes da distribuição orçamentária. Por isso, serão utilizados dados secundários, principalmente aqueles disponibilizados pelo Conselho Nacional de Justiça e outros estudos estatísticos que propiciem uma melhor compreensão do fenômeno estudado.

\section{ACESSO À JUSTIÇA: CONCEITO E HISTÓRICO}

\subsection{INTROITO}

A ideia de proporcionar acesso à justiça, enquanto porta de entrada para uma instituição que vise assegurar os direitos e deveres, está intimamente relacionada à história da fixação das bases do Estado de Direito (SOUZA, 2016). "Veja-se que o Estado monopolizou o poder jurisdicional, e isso a um ponto tal que, em geral, qualifica como crime o exercício da autotutela. Portanto, mais do que uma razão jurídica, a colocação de tribunais à disposição das pessoas é um corolário lógico" (SOUZA, 2009).

Expressamente, a Constituição de 1824 já trazia em seu art. 179, XXX, que "todo o Cidadão poderá apresentar por escripto ao Poder Legislativo, e ao Executivo reclamações, queixas, ou petições, e até expôr qualquer infracção da Constituição, requerendo perante a competente Auctoridade a effectiva responsabilidade dos infractores". Tal comando legal 


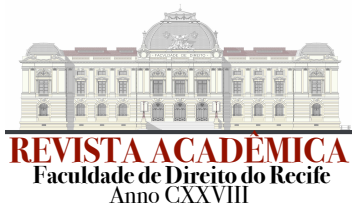

versava, portanto, sobre o direito à petição, não havendo que se falar no direito ao acesso à justiça propriamente dito.

$\mathrm{Na}$ história das Constituições brasileiras, a primeira menção expressa do acesso ao judiciário como direito fundamental se deu com a Constituição de 1946, que trazia em seu art. 141, §4" “a lei não poderá excluir da apreciação do Poder Judiciário, qualquer lesão ou ameaça de direito individual". Do mesmo modo que na constituição anterior, ainda não era possível se falar em acesso à justiça tal como se concebe hoje.

A presença da ideia de acesso ao judiciário em conjunto com as garantias fundamentais processuais se encontra presente na Convenção Interamericana sobre Direitos Humanos de São José da Costa Rica (1969), da qual o Brasil é signatário. Segundo reza seu $\operatorname{artigo} 8^{\circ}$ :

Toda pessoa tem direito de ser ouvida, com as garantias e dentro de um prazo razoável, por um juiz ou tribunal competente, independente e imparcial, estabelecido anteriormente por lei, na apuração de qualquer acusação penal contra ela, ou para que se determinem seus direitos ou obrigações de natureza civil, trabalhista, fiscal ou de qualquer natureza.

No entanto, o conceito do direito ao acesso à justiça vem ganhando outros contornos e ampliando sua abrangência. Para entendermos melhor sobre seu significado, será apresentada, em seguida, uma abordagem da evolução conceitual, passando pela história do acesso à justiça no Brasil, e, logo após, serão pontuadas algumas dificuldades apresentadas pela doutrina no que pertine ao sistema atual brasileiro.

\subsection{CONCEITO}

O termo "acesso à justiça" vem sendo utilizado para indicar dois objetivos básicos do sistema jurídico. Primeiro, é visto como o sistema que permite às pessoas reivindicarem seus direitos e/ou resolverem seus litígios sob a tutela do Estado, que deve ser verdadeiramente acessível a todos. Segundo, que este sistema deve produzir resultados que sejam individual e socialmente justos (CAPPELLETTI; GARTH, 1988, p. 08).

Assim sendo, de logo, esclarece-se que o acesso à justiça não deve ser confundido tão somente com o acesso ao Poder Judiciário. “Acesso à justiça significa a possibilidade de 


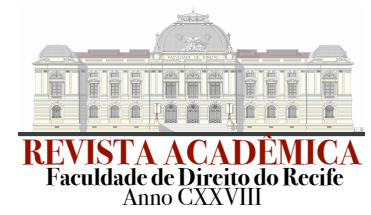

lançar mão de canais encarregados de reconhecer direitos, de procurar instituições voltadas para a solução pacífica de ameaças ou de impedimentos a direitos” (SEDEK, 2009, p. 175).

$\mathrm{O}$ estudo referente ao acesso à justiça vem sendo objeto de certo destaque na ciência jurídica desde as décadas de sessenta e setenta, quando se passou a investigar, ainda mais, maneiras de se entender e efetivar esse direito (BRASIL, 2014, p. 13).

Uma das obras merecedoras de destaque, já desse período, foi produzida por Boaventura de Souza Santos, que em estudo empírico realizado na favela do jacarezinho, no Rio de Janeiro, demonstrou como a ausência de acesso à justiça oficial do Estado leva à construção de outras ordens jurídicas não estatais em ambientes que não têm o devido aparelhamento estatal (SANTOS, 1999).

Outra produção bibliográfica bastante importante já desse período, desta vez numa perspectiva mais técnico-jurídica, é a de Mauro Cappelletti em coautoria com Bryant Garth, publicada pela primeira vez em 1978. Esse trabalho é o resultado do chamado Projeto Florença, em que os autores fazem um profundo estudo sobre o tema acesso à justiça em diversas localidades do mundo e expõem criticamente algumas atitudes concretas empregadas por alguns Estados como medidas de enfrentamento das dificuldades encontradas.

Para Cappelletti e Garth (1988), o estudo e o respeito ao acesso à justiça são de fundamental importância para o Estado Democrático de Direito, reconhecendo-o como o direito fundamental que assegura a efetividade ao demais direitos. Em suas palavras, "o acesso à justiça pode, portanto, ser encarado como o requisito fundamental — o mais básico dos direitos humanos - de um sistema jurídico moderno e igualitário que pretenda garantir, e não apenas proclamar os direitos de todos" (CAPPELLETTI; GARTH, 1988, p. 12).

Essa preocupação de se efetivar direitos anunciados tornou-se o motor principal para a discussão do acesso à justiça, pois, "sem o direito de recorrer à justiça, todos os demais direitos são letras mortas, garantias idealizadas e sem possibilidades de concretização, [...] caso não se considere como prioritário o acesso à justiça todos os demais esforços correm o risco de não perdurar e se desfazer" (SADEK, 2009, p. 170). Desta forma, o acesso à justiça funciona como mediador entre o direito material e as suas garantias constitucionais.

Quando Cappelletti e Garth (1988) publicaram o Relatório de Florença, em 1978, eles destacaram alguns obstáculos que impossibilitavam a efetivação do acesso à justiça. Foram 


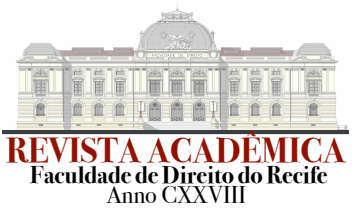

elencados: a) os custos relativos à ação judicial; b) as diferentes possibilidades das partes; e, c) os problemas especiais dos interesses difusos.

Ao analisar tais dificuldades os autores apontam que chegaram a um padrão: primeiro, que "os obstáculos criados pelos sistemas jurídicos são mais acentuados para as pequenas causas e para os autores individuais, especialmente os pobres" (CAPPELLETTI; GARTH, 1988, p. 28); e segundo, que "as vantagens pertencem de modo especial aos litigantes organizacionais, adeptos do uso do sistema judicial para obterem seus próprios interesses" (CAPPELLETTI; GARTH, 1988, p. 28).

As soluções práticas foram apresentadas pelos autores em três fases históricas, por eles denominadas "ondas". A primeira onda refere-se à assistência judiciária para os pobres; a segunda trata de modelos legislativos que possibilitavam a representação dos interesses difusos; e, a terceira, associa-se o que eles chamaram de "um novo enfoque de acesso à justiça”. Esta última "centra sua atenção no conjunto geral de instituições e mecanismos, pessoas e procedimentos utilizados para processar e mesmo prevenir disputas nas sociedades modernas" (CAPPELLETTI; GARTH, 1988, p. 67-68), sem deixar de utilizar técnicas das outras duas.

Ainda sobre a terceira onda, são apresentadas pelos autores algumas tendências para o enfrentamento das barreias do acesso à justiça. São exemplos delas: a reforma procedimentos judiciais gerais; criação de outros métodos de decisão judicial como a conciliação, a arbitragem e a aplicação de penalidades às partes por não aceitarem acordos tidos como razoáveis pelas cortes; criação de procedimentos especiais para causas com relevância social, como trabalhista, consumidor e pequenas causas; mudança de métodos de prestação de serviços jurídicos com a possibilidade de utilização de "parajurídicos" e seguros para custos dos processos; e, por fim, a simplificação do direito para torná-lo mais acessível à população.

Fixado o conceito de acesso à justiça, pode-se passar a analisar como tal direito veio sendo trabalhado no Brasil via legislativa. Para tanto, entende-se ser interessante apresentar a evolução legislativa através das três ondas referidas por Cappelletti e Garth (1988).

\subsection{HISTÓRICO DO ACESSO À JUSTIÇA NO BRASIL SEGUNDO AS TRÊS “ONDAS”}




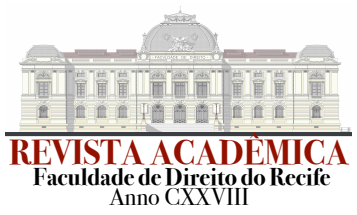

Partindo para a análise histórica do acesso à justiça no Brasil, podemos reconhecer alguns marcos das três ondas apresentadas por Cappelletti e Garth (1988) da maneira explicitada a seguir.

Sobre a primeira onda, que trata do acesso à justiça aos pobres, podemos citar como marco histórico a promulgação da Lei de $\mathrm{n}^{0} 1.060$ de 1950, que tratava da assistência judiciária no Brasil, e concedia a isenção de custas, honorários sucumbenciais, dentre outros benefícios, aos que não tinham condições de arcar com os custos dos processos.

A segunda onda pode ser percebida com a promulgação da Lei de $n^{\circ} 4.717 / 65$, que regulava a ação popular, já havendo, portanto, a abertura para a possibilidade de pleitos de interesses difusos e coletivos no Brasil.

Mas foi com o advento da Constituição de 1988 que o acesso à justiça passou a ter maior destaque no cenário brasileiro, com a previsão de mecanismos integrados de promoção a uma ordem jurídica justa (terceira onda).

Com a ampliação do direito ao acesso à justiça e com expressa previsão no título de direitos e garantias fundamentais (notadamente nos incisos XXXIV e XXXV, do art. $5^{\circ}$ ), a nova Carta Magna brasileira trouxe diversas inovações referentes ao tema. Passou a garantir assistência jurídica integral e gratuita aos que possuem insuficiência de recursos (art. $5^{\circ}$, inciso LXXIV); tratou do mandado de segurança coletivo (art. $5^{\circ}, \mathrm{LXX}$ ), do mandado de injunção (art. $5^{\circ}, \mathrm{LXXI}$ ); aumentou a legitimidade para propor ações coletivas por meio dos sindicatos (art. $8^{\circ}$, III) e atividades associativas (art. $\left.5^{\circ}, \mathrm{XXI}\right)$. Acrescenta-se, ainda, o avanço caracterizado pelo fortalecimento do Ministério Público (art. 127, caput, $\S 2^{\circ}$ e $3^{\circ}$, e art. 129), da advocacia (art. 133) e da defensoria pública (art. 134), trazendo proteção constitucional a tais carreiras jurídicas.

Outrossim, em prosseguimento do quanto determinando na Constituição, surgiram leis especiais relativas ao tema: em 1989, a Lei $\mathrm{n}^{\mathrm{o}}$ : 7.853, que trata da tutela de interesses "coletivos ou difusos" das pessoas portadoras de deficiências. Em 1990, promulga-se um novo Estatuto da Criança e do Adolescente e institui-se o Código do Consumidor. Em 1995, reformula-se o tratamento das ações de pequenas causas, com a criação dos juizados especiais cíveis e criminais através da Lei de $n^{\circ} 9.099$. Em 2009, surge a Lei de $n^{\circ} 12.016$ que regula o Mandado de Segurança Coletivo. 


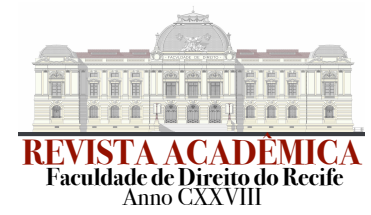

Assim, pode-se perceber que a legislação vem evoluindo no sentido de trazer novas possibilidades e abertura de novas portas aos cidadãos para o acesso à justiça. No entanto, tal acessibilidade acaba por trazer uma demanda maior aos órgãos do poder judiciário, que não tem conseguido suportar toda a entrada de processos, nem oferecer a tutela jurídica adequada. Sobre os problemas do acesso à justiça no Brasil, trata o tópico seguinte.

\subsection{OBSTÁCULOS PARA O ACESSO À JUSTIÇA NO BRASIL}

Quando da publicação do livro de Cappelletti e Garth (1988), eles já apontavam para alguns problemas inerentes ao acesso à justiça e propuseram algumas soluções. Em razão do tempo da publicação e por terem sido feitas algumas considerações que não refletiriam a realidade brasileira, optamos por utilizar como parâmetro base para o diagnóstico do acesso à justiça no Brasil, o trabalho de Sadek (2014), que possui grande influência do clássico Projeto Florença, mas que faz as devidas modificações/adaptações sobre a realidade brasileira.

Sadeck (2014, p. 57) faz sua exposição referente aos obstáculos que enxerga no Brasil, dividindo-os em três etapas: I - o ingresso à obtenção de um direito; II - os caminhos posteriores à entrada e, III - a saída.

O primeiro obstáculo apresentado pela Autora na porta de entrada é o desconhecimento, pela população, de seus direitos em decorrência da grande desigualdade social existente no país (SADEK, 2014, p. 59). Outro problema na porta de entrada seria que o Poder Judiciário acabaria por atender a um determinado grupo de pessoas em detrimento de outros. “O Judiciário acaba por se transformar em órgão estatal responsável pela solução de litígios sobretudo do setor público federal, estadual e municipal, dos bancos e das empresas prestadoras de serviço" (SADEK, 2014, p. 60).

Assim afirma a Autora, pois os maiores litigantes do Brasil são a Caixa Econômica Federal, a União, o INSS, os bancos, as empresas de telefonia e os municípios (SADEK, 2014, p. 60). Dessa forma, embora haja um grande volume de processos no Brasil, "a porta de entrada atrai um tipo de litigante e desencoraja ou se fecha para a grande massa de indivíduos incapazes de manejar instrumentos de efetivação de seus direitos, produzindo um paradoxo: 


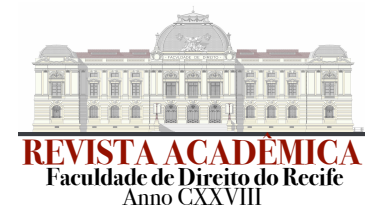

demandas demais e demandas de menos" (SADEK, 2014, p. 60), ou seja, demandas demais para uns e demandas de menos para outros.

Por outro lado, como problema existente nos "caminhos posteriores à entrada", teríamos a lentidão de solução dos processos. Segundo o CNJ, "o tempo médio do processo baixado no Poder Judiciário é de 1 ano e 9 meses na fase de conhecimento e de 4 anos e 10 meses na fase de execução no $1^{\circ}$ grau de jurisdição e de 8 meses no $2^{\circ}$ grau" (BRASIL, 2017a, p. 132). Já no que se refere a processos que ainda estão esperando para serem baixados, nota-se que houve aumento significativo do estoque "superior ao da baixa tanto no $2^{\circ}$ grau, com 2 anos e 5 meses de duração (3,6 vezes superior ao tempo de baixa), quanto no $1^{\circ}$ grau, nas fases de conhecimento, com 4 anos e 4 meses (2,5 vezes superior ao tempo de baixa), e de execução, com 7 anos e 4 meses (1,5 vez superior ao tempo de baixa)" (BRASIL, 2017a, p. 133).

Nesse ponto, vale avaliar a quantidade de magistrados e servidores existentes no Poder Judiciário como fator potencial de explicação da morosidade da justiça.

A quantidade de juízes por habitantes na justiça brasileira é de 8,16 juízes para cada 100 mil habitantes (BRASIL, 2017a, p. 60), valor superior ao que o ONU indica como ideal, que seria de 7 juízes para cada 100 mil (AMB, 2016). A produtividade do juiz brasileiro também é alta, se comparada com os juízes dos países desenvolvidos, inclusive. Em 2013, os magistrados brasileiros julgaram uma média de 1.684 ações, no mesmo período "a taxa média nos 42 países pesquisados é de 736 processos por juiz ao ano. O Brasil está atrás apenas da Áustria, segunda colocada do ranking, com 1.848 processos por magistrado, e da Dinamarca, com 8.075 processos julgados" (AMB, 2015. p. 15). Em 2016, foram julgados, em média, 1.749 processos por juiz, sendo cada juiz responsável em média por 6.696 (BRASIL, 2017a, p. 70).

Assim sendo, a quantidade de juízes é compatível, quando não superior, com outros países desenvolvidos e de acordo com o recomendado pela ONU. A produtividade também é compatível. Então, qual seria o real motivo para a lentidão do judiciário? Sadek (2014, p. 61) vai imputar tal lentidão dos processos no Brasil “à legislação, o número de recursos, o formalismo, o tratamento dado às demandas individuais repetitivas, o número de juízes, a 


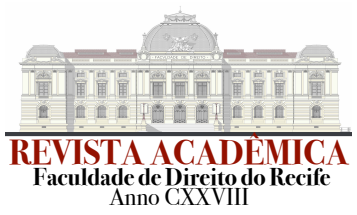

infraestrutura, o gerenciamento, o orçamento, a mentalidade de magistrados e dos demais operadores do direito".

Tais dificuldades, na entrada e dentro do sistema, causam, segundo Sadek (2014), problemas com a saída do que foi judicializado, haja vista que a demora em resolver o litígio acaba provocando uma perda na credibilidade do sistema jurídico. "Do ponto de vista da credibilidade da justiça, independentemente do peso relativo e da avaliação que se faça sobre cada uma dessas causas, são inegáveis os efeitos perniciosos provocados pelos meandros a serem percorridos e das etapas a serem ultrapassadas até que se chegue à porta de saída" (SADEK, 2014, p. 62).

Percebe-se, portanto, que algumas dessas causas apresentadas pela Autora se referem a questões diretamente relacionadas à escassez de recursos que são utilizados pelo judiciário, como o número de juízes, a infraestrutura, o gerenciamento de recursos e o orçamento. Dessa maneira, importante é fazer uma - ainda que breve - explanação sobre como os recursos investidos têm influência na capacidade e qualidade dos serviços prestados pelo Estado aos seus cidadãos, inclusive os serviços judiciais.

\section{DIREITO, ESCASSEZ E O PODER JUDICIÁRIO BRASILEIRO}

\subsection{INTROITO}

O presente capítulo trata sobre como os direitos, inclusive o de acesso à justiça (que exigem uma forte atuação do Estado), influenciam no orçamento público e encontram nele limites que não devem ser ignorados quando de seu estudo.

Primeiramente, cumpre esclarecer que este trabalho não se fixa na ideia de que existam direitos positivos - com custos - e direitos negativos - sem custos. Todos direitos são positivos, conforme será melhor explicado adiante. Não há como assegurar direitos sem que isso onere de alguma forma o orçamento do Estado, seja pelas forças policiais - para assegurar a liberdade e proteger a propriedade privada -, seja pela formação e manutenção dos Tribunais - inclusive para assegurar o voto, por exemplo. "Direitos não nascem em 


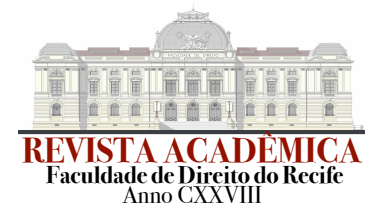

árvores", como já exposto por Galdino (2005). Então, cientificamente, como podemos classificar as prestações do Estado que visam assegurar direitos por ele prometidos?

Gustavo Amaral (2001, p. 81) nos propõe a seguinte classificação: existem direitos que são "parcialmente independentes" e existem direitos que são "dependentes" da ação estatal. Os primeiros, tais como a liberdade de expressão e a liberdade de credo, não dependem de uma ação imediata do Estado. Em tais casos, o Estado vai apenas decidir, quando houver conflitos entre direitos, qual direito será reconhecido, além de garantir todo o aparato judicialadministrativo, para, caso haja sua violação, o cidadão que se sinta prejudicado possa a ele recorrer e ter suas expectativas solvidas. Por isso são independentes, mas essa independência se dá apenas parcialmente.

Já os direitos dependentes não funcionam assim. Eles precisam que o Estado atue de forma imediata para que seus direitos sejam tutelados. Não há dúvida acerca do reconhecimento da existência do direito ou quem o está exercendo da forma correta. Há dúvidas sobre a quem será concedida a tutela estatal prometida e quais serão os critérios adotados para tal escolha. "A competição é, portanto, por recursos escassos" (AMARAL, 2000, p. 83). Já que as necessidades são ilimitadas e o orçamento não, os direitos dependentes disputam entre si quais deles serão prontamente atendidos e em qual medida isso ocorrerá.

Ou seja,

quanto aos "direitos parcialmente independentes", será sempre possível ao magistrado dar ordens para que o Estado se abstenha e essas ordens sejam cumpridas. Não há questões orçamentárias que impeçam o cumprimento de uma ordem de habeas corpus ou uma liminar determinando uma liberação de mercadorias, o não impedimento de uma manifestação religiosa, política ou artística, muito embora a obtenção dessas ordens demande um aparato judicial custoso. Já quanto aos "direitos dependentes", o consumo de recurso é inexorável (AMARAL, 2000, p. 84).

A tese sustentada no presente trabalho é que o acesso à justiça é um direito dependente da ação estatal. Por isso, a teoria dos custos do Direito merece um destaque e um estudo mais aprofundado quando se trabalha com o acesso à justiça. $\mathrm{O}$ que passará a ser tratado no tópico seguinte.

\subsection{A TEORIA DOS CUSTOS DO DIREITO}




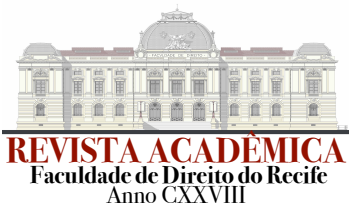

Até aqui já foi possível mostrar a importância do estudo sobre a relação entre a carência de recursos e a efetivação do direito fundamental do acesso à justiça, tornando imperiosa, porém, uma reflexão sobre a disponibilidade de orçamento para os Tribunais e seus gastos para a promoção do acesso à justiça, pois, “o orçamento é o caminho por meio do qual se permite realizar políticas públicas, essenciais à concretização dos direitos fundamentais" (MACHADO, 2010, p. 01).

A reflexão entre os direitos fundamentais e seus custos suportados pelo Estado, normalmente se baseava por meio de uma dicotomia entre direitos positivos e direitos negativos. De acordo com tal classificação, os direitos positivos seriam aqueles que, para sua proteção, seria necessário haver gastos por parte do Estado, sendo eles geralmente ligados a direitos prestacionais sociais, como saúde, educação e previdência. Por outro lado, seriam negativos quando não houvesse a necessidade de despesa pública para a sua tutela, já que a abstenção do Estado bastaria, como o direito ao sufrágio universal e à livre manifestação.

Ocorre que, a partir do convite de se levar a sério os estudos sobre os custos decorrentes da tutela dos direitos fundamentais, feito por Holmes e Sunstein (1999), a ciência jurídica passou a ter outra concepção sobre a importância dos custos gerenciais dos direitos. Isto porque, para os autores estadunidenses, todos os direitos são positivos e, por tal razão, possuem custos. Portanto, a proteção de qualquer direito fundamental (seja a liberdade ou a seguridade social) gera custos ao Estado e deve ser levado em conta quando da reflexão sobre sua efetivação.

Essa maneira de pensar nos proporciona uma maior inteligência sobre a realidade estudada, uma vez que "a retórica em torno da gratuidade dos direitos em geral é deveras prejudicial, simplesmente por ignorar ou desconsiderar - o que resulta no mesmo - os elevadíssimos custos subjacentes às prestações públicas necessárias à efetivação dos direitos fundamentais" (GALDINO, 2005, p. 325).

Assim, é preciso entender que há uma relação entre a disponibilidade de orçamento e a capacidade de resguardar direitos que decorre da escassez de recursos e da quantidade incontáveis de bens a se proteger. "A escassez de recursos e a escassez de meios para satisfazer direitos, mesmo fundamentais, não pode ser descartada. Surgindo esta, o Direito precisa estar aparelhado para dar respostas" (AMARAL, 2002, p. 185). 


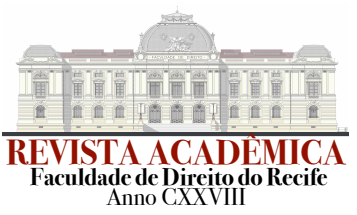

Por isto, a valiosa contribuição de Holmes e Sunstein (1999, p. 97) ao demonstrar como o resguardo do Direito acaba por responder à quantidade de recurso sobre ele investido, tornando visível que, quando a economia vai bem e se investe recursos para proteger determinado direito, ele acaba por ter maior tutela, ao passo que, quanto menos se investe na proteção (seja por falta de recurso ou má vontade política), o direito tende a se retrair em efetividade.

Nesse sentido, é importante destacar que não é apenas a quantidade de recursos disponível para gasto do Estado que determina a proteção do direto. "O que usualmente frustra a efetivação de tal ou qual direito reconhecido como fundamental não é a exaustão de um determinado orçamento, mas sim a opção política (justa ou injusta, sindicável judicialmente ou não) de não se gastar dinheiro com aquele mesmo 'direito"” (GALDINO, 2005, p. 235).

Assim sendo, é neste cenário de tensão entre acesso à justiça e disponibilidade de recursos para o Poder judiciário que se podem extrair frutíferas reflexões teóricas sobre o assunto. No entanto, é preciso que se demonstre, de logo, o quanto se gasta com o Poder Judiciário no Brasil, e suas repercussões tanto no orçamento quanto na prestação de serviço judicial forense.

\subsection{O JUDICIÁRIO E SEUS CUSTOS NO BRASIL}

Segundo dados do Conselho Nacional de Justiça, o Poder judiciário custou aos cofres públicos, em 2016, o valor de 84,8 bilhões de reais, o que representa 1,4\% do Produto Interno Bruto do Brasil, ou, ainda, a 2,5\% dos gastos totais da União, dos estados, do Distrito Federal e dos municípios (BRASIL, 2017a, p. 51). Esse custo equivale a R\$ 411,73 por habitante, havendo uma tendência de constante crescimento com o passar dos anos (BRASIL, 2017a, p. 51).

Dentre os gastos operacionais do Poder judiciário brasileiro, aproximadamente $90 \%$ de suas despesas são com gastos relativos aos recursos humanos, o que compreende, além da remuneração com magistrados, servidores, inativos, terceirizados e estagiários, todos os demais auxílios e assistências devidos, tais como auxílio-alimentação, diárias, passagens, 


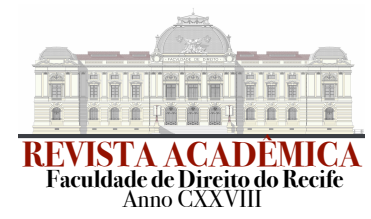

entre outros (BRASIL, 2017a, p. 53). Os 10\% restantes são gastos com despesas de capital $(2,2 \%)$ e despesas correntes $(8,3 \%)$ que somados representam o valor de $\mathrm{R} \$ 8,9$ bilhões (BRASIL, 2017a, p. 53).

O custo para o orçamento público de um magistrado brasileiro é de, em média, R\$ 47,7 mil; o dos servidores fica em torno de $\mathrm{R} \$ 13,7$ mil; os terceirizados, por sua vez, $\mathrm{R} \$ 4$ mil e os estagiários R \$ 871,14 (BRASIL, 2017a, p.56). Tais valores variam significativamente por Tribunal. Por isso, é importante registrar a média em cada área do Poder Judiciário, o que se faz aqui por meio do seguinte gráfico:

Gráfico 1 - Despesa média mensal com magistrado e servidor, por tribunal

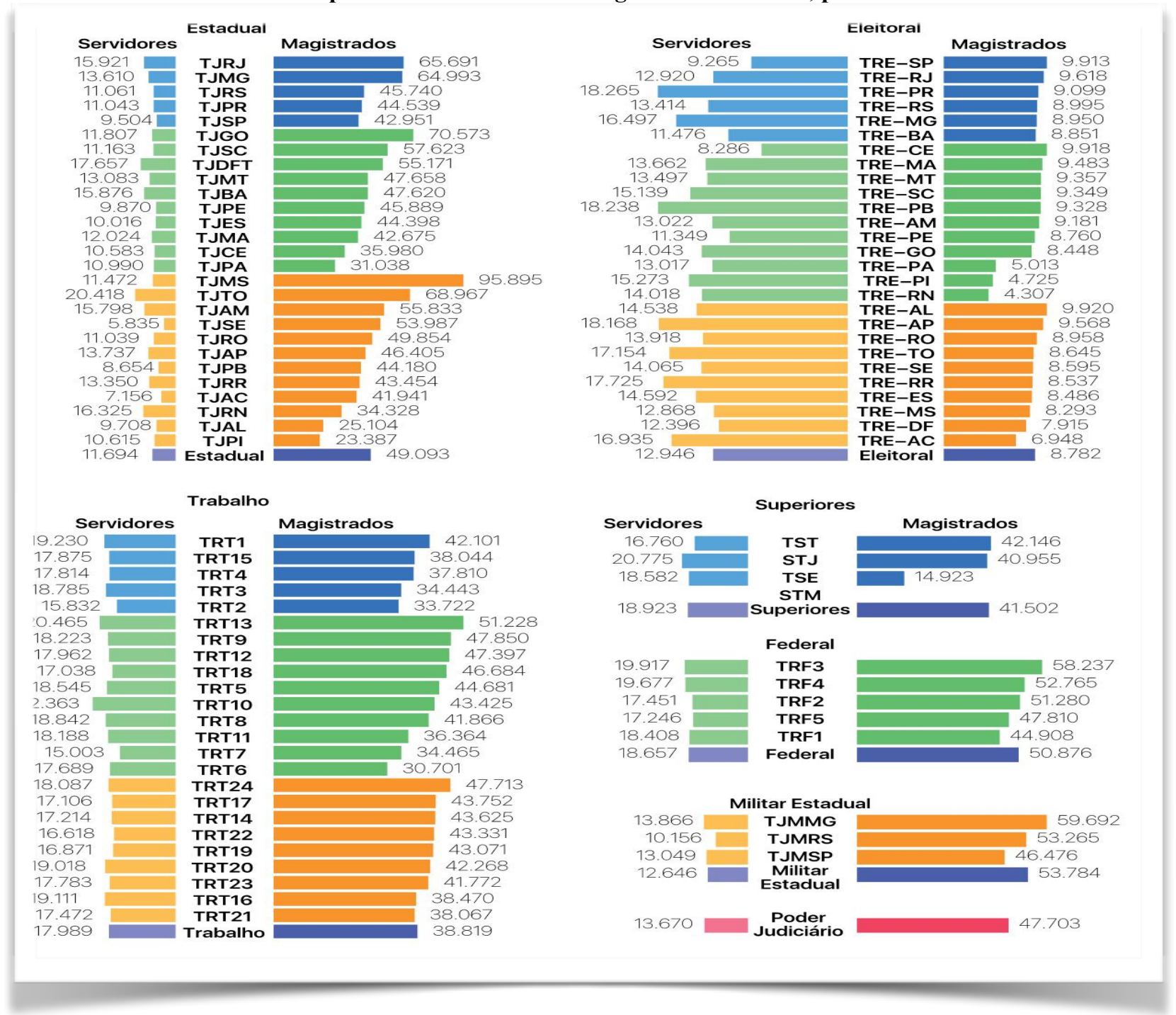

Fonte: (CNJ, 2017a, p. 58) 


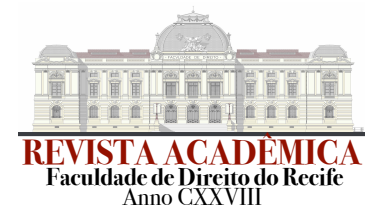

Destaque-se, da leitura do gráfico supra, a desigualdade existente entre o Tribunais no país. Note-se que com o que se gasta em média por um magistrado do Tribunal de Justiça de Mato Grosso do Sul (R\$ 95.895,00), daria para custear dois ministros de qualquer Tribunal Superior, que recebem, em média, R\$ 41.502,00, e ainda sobraria R\$12.891,00. Ou, ainda, com o valor gasto pelos magistrados do Mato Grosso do Sul, poder-se-ia pagar por quatro juízes do Tribunal de Justiça do Piauí (R \$ 23.387,00). Sendo que estes, inclusive, custam, em média, quase o mesmo que um servidor ( $\mathrm{R} \$ 20.418,00)$ do Tribunal de Justiça do Tocantins.

Em que pese possa se considerar grande a despesa do Poder Judiciário para os cofres públicos, há de se ressaltar, porém, que foi em razão da atividade jurisdicional que, durante o ano de 2016, o fisco recebeu cerca de $\mathrm{R} \$ 39,04$ bilhões, o que representou um retorno da ordem de $48 \%$ das despesas efetuadas (BRASIL, 2017a, p. 53). A Justiça Federal é o segmento responsável pela maior parte das arrecadações, 48\% do total do Poder Judiciário, e único capaz de retornar aos cofres públicos valor superior às despesas (BRASIL, 2017a, p. 34), conforme dispõe o seguinte gráfico:

Gráfico 2 - Percentual de receitas em relação às despesas, por ramo de Justiça

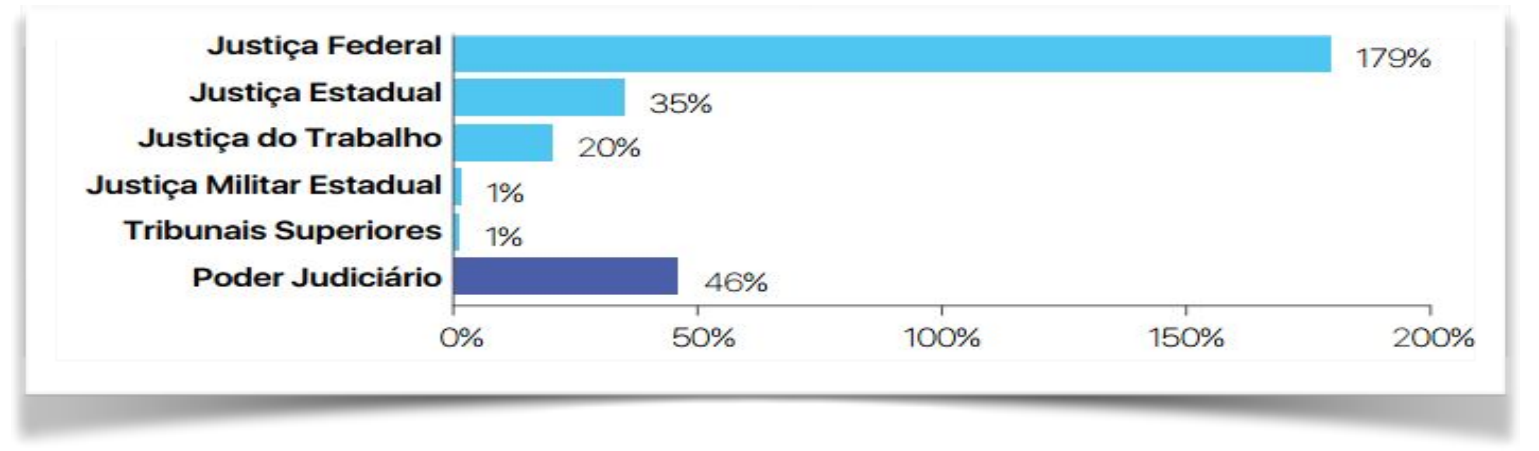

Fonte: (CNJ, 2017a, p. 58)

Ocorre que, apesar de tais dados serem capazes de fornecer uma boa noção do quanto custa efetivamente o Poder Judiciário no Brasil, eles não são capazes de, por si só, demonstrar se os valores investidos são suficientes ou insuficientes para o destino a que se propõe. Por isso, importante é trazermos alguns parâmetros comparativos a fim de situarmos melhor a realidade brasileira e sua relação com as despesas orçamentárias do judiciário.

Nesse ponto, interessante trazer o estudo realizado por Luciano Da Ros (2015a, 2015b) que traz uma série de dados comparativos entre o Brasil e outros países referentes aos 


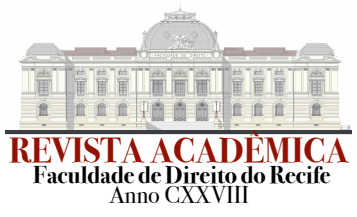

custos do Poder Judiciário em relação ao PIB. Tais dados podem ser sintetizados por meio do seguinte gráfico:

Gráfico 3 - Despesa do Poder Judiciário como (\%) percentual do Produto Interno Bruto, países selecionados

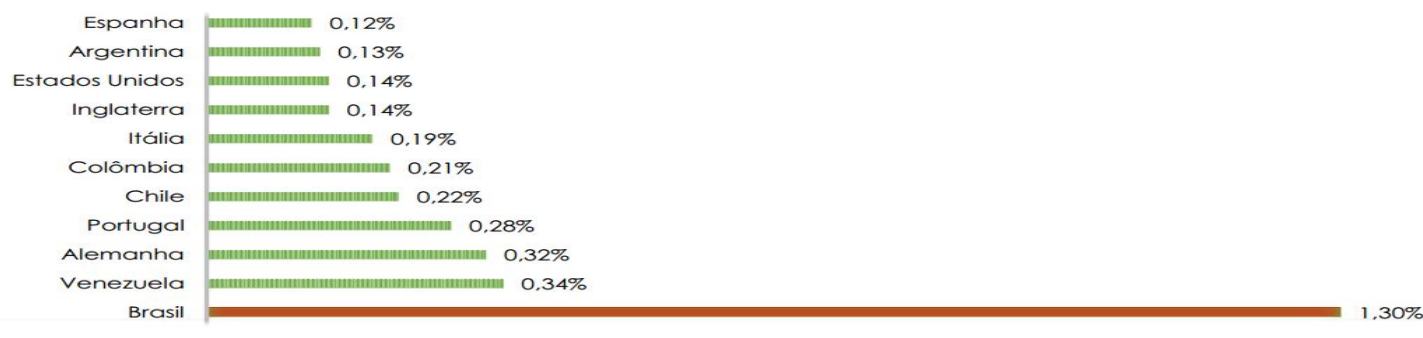

Fonte (ROS, 2015a, p. 4)

O que se percebe aqui é que, em relação ao PIB, o gasto pelo judiciário no Brasil é um dos mais caros no mundo. "O orçamento destinado ao Poder Judiciário brasileiro é muito provavelmente o mais alto por habitante dentre todos países federais do hemisfério ocidental" (ROS, 2015a, p. 4).

Tais gastos, em 2014, fizeram com que o Brasil tivesse um dos mais altos custos por decisão judicial na área pesquisada pelo Autor. "Um cálculo simples, dividindo o orçamento total destinado para o Poder Judiciário pelo total de casos baixados, indica que o custo por cada decisão judicial é, em média, de $\mathrm{R} \$ 2.248,93$ ou $€$ 691,98 no Brasil, e não passando de R\$ 1.679,15 ou € 516,66 na Itália” (ROS, 2015b, p. 10).

Para Ros (2015, p. 05) tal custo elevado se dá não pela quantidade de juízes - já que seria compatível com a média dos demais países da pesquisa - mas, sim, pela quantidade de servidores que acompanham a atividade judicial.

No entanto, essa necessidade de maior quantidade de pessoas trabalhando com os juízes não se dá por acaso. “A contratação de mais assessores e estagiários no Poder Judiciário brasileiro vem provavelmente sendo a principal forma utilizada para lidar com a sua volumosa e crescente carga de trabalho, [...] mesmo porque segue lenta a expansão do número de magistrados" (ROS, 2015b). Ora, como a demanda é muito grande, e não há recurso para se expandir muito mais a quantidade de magistrado, investe-se em servidores auxiliares como forma de desafogar minimamente o trabalho dos juízes. 


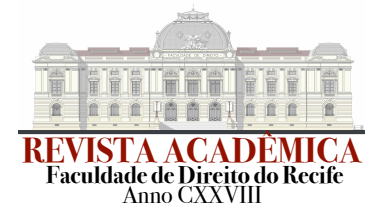

Esse alto volume processual é visto como outro motivo pelo qual há tamanha diferença de investimento do Estado no Poder Judiciário. Enquanto, no Brasil, à época da pesquisa internacional (2013), havia cerca de 14.000 novos casos ingressando no Poder Judiciário anualmente para cada 100.000 habitantes, "a média é muito inferior nos países europeus para os quais pudemos calcular estes dados, atingindo 4.877 novos casos por 100.000 habitantes ao ano na França, 7.922 em Portugal, e 9.287 na Itália” (ROS, 2015a, p. 10).

Atualizando-se os dados para os dias atuais, "durante o ano de 2016, ingressaram 29,4 milhões de processos e foram baixados 29,4 milhões. Um crescimento em relação ao ano anterior na ordem de 5,6\% e 2,7\%, respectivamente" (BRASIL, 2017a, p. 65). "Em média, a cada grupo de 100.000 habitantes, 12.907 ingressaram com uma ação judicial no ano de 2016". Veja-se:

Gráfico 4 - Casos novos por 100.000 habitantes, por ramo de Justiça

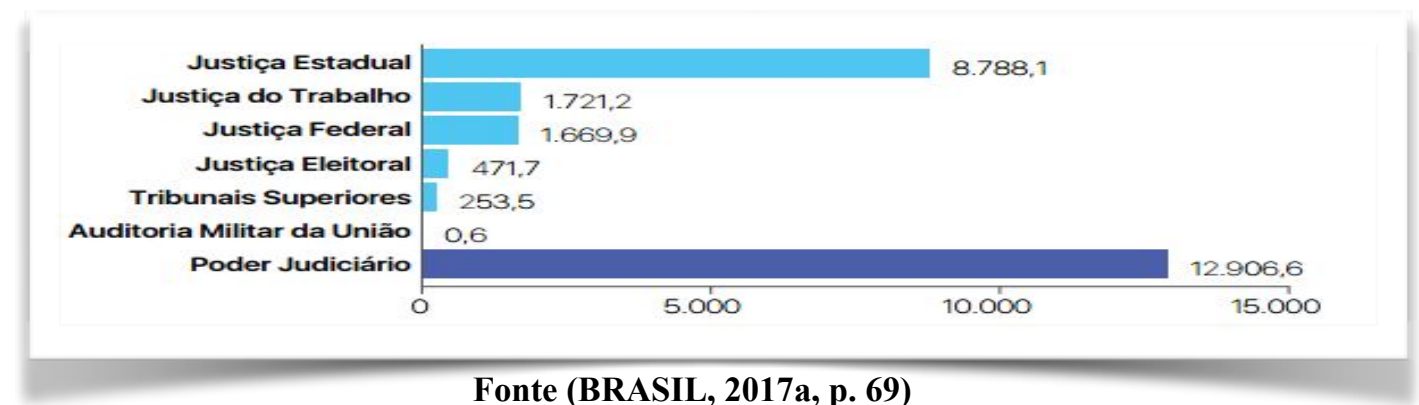

Além dos já citados motivos dessas diferenças de investimento, Ros (2015a, p. 8) aponta também o "legado de instituições autoritárias, o longo período de incerteza jurídica derivado do cenário de sucessivas crises econômicas das décadas de 1980 e 1990, e as abissais desigualdades socioeconômicas existentes" como outros fatores importantes para entendermos tais discrepâncias.

Uma vez fixados os parâmetros acerca o que se entende ser o acesso à justiça e a que se preocupa a teoria dos custos do direito, pode-se passar para uma apresentação ainda mais clara de como ambos os assuntos convergem entre si. 


\section{ACESSO À JUSTIÇA E ESCASSEZ DE RECURSO - A REALIDADE DAS ESCOLHAS DISJUNTIVAS ORÇAMENTÁRIAS}

\subsection{ACESSO À JUSTIÇA E AS ESCOLHAS DISJUNTIVAS}

A vantagem em levar a discussão sobre o acesso à justiça como um direito dependente da ação direta estatal é que isso nos permite perceber que, em verdade, o acesso à justiça não deve ser questionado no sentido de que se "A" ou "B" possuem tal direito. Todos possuem o direito ao acesso à justiça, como já foi explanado no capítulo 02. A diferença que existe se dá no campo da proteção e possibilidade de se salvaguardar o direito de "A" e de "B", tal como acontece com todo direito dependente da ação estatal.

Em verdade, o que há é uma concorrência entre o acesso à justiça e todos os outros direitos dependentes, como saúde, educação, moradia, etc., que também são de grande importância e disputam entre si recursos orçamentários do Estado. A importância de elevar tal discussão para o plano orçamentário é que "o Direito, como disciplina prática, não pode ser indiferente às consequências das concepções que adota, e a teoria jurídica não deve tentar ‘tapar o sol com a peneira', fingindo que é possível realizar o impossível” (SARMENTO, 2016, p. 97-98).

Assim sendo, "será possível ocorrer situação onde seja necessário realizar opção disjuntiva entre atender um reclame ou outro, embora também teoricamente ambos devam ser atendidos, pois o recurso não é suficiente para o atendimento de todos" (AMARAL, 2000, p. 130). Dessa forma, "por depender de recursos escassos, os direitos demandam ou implicam em escolhas disjuntivas de natureza financeira" (AMARAL, 2000, p. 96) e toda vez que se atende a um, nega-se o atendimento a outro.

É preciso ter em mente, portanto, que "as escolhas alocativas acabam sendo também desalocativas, pois subtraem 'fatias do bolo' dos recursos existentes, mesmo quando isso não seja explicitado" (SARMENTO, 2016, p. 229). Dessa maneira, quando o Estado escolhe pagar o salário a um juiz, por exemplo, ele está escolhendo também não utilizar esse recurso para pagar a médicos, defensores públicos, professores, policiais, enfermeiros, e assim sucessivamente. Do mesmo modo, a construção ou a manutenção de um fórum mais próximo 


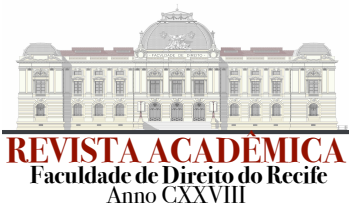

da residência do jurisdicionado, pode implicar na não construção de uma unidade básica de saúde, da não reforma de determinada rodovia ou da não criação de novas creches para as crianças.

Nesta senda, para a satisfação das pretensões originadas dessa dimensão em que é necessário consumo direto de recursos escassos, torna-se inexorável a tomada de decisões alocativas (AMARAL, 2000, p 198-199), de cunho eminentemente político, que deve levar em consideração o quanto se pode, se deve ou se quer gastar para proteger um direito em detrimento de outro.

Essa decisão alocativa de bens e recursos deve ser feita por meio de múltiplos procedimentos, critérios e agentes (GALDINO, 2005, p. 156) nem sempre fáceis de ponderar. Isso porque, quando entramos nos reinos dos valores axiológicos, é muito difícil se definir a priori o que vale mais, em razão da circunstancialidade dos valores. O que vale mais: um médico ou um mecânico? A resposta a esta pergunta vai depender mais das circunstâncias do que a atividade em si. Com o carro quebrado no meio de uma rodovia deserta, decerto, melhor ter a companhia de um mecânico do que do mais hábil oftalmologista. O juízo de valor se inverte, no entanto, se o problema a ser resolvido for uma questão que abarque a visão de alguém e não o motor de um carro.

Assim sendo, enquanto para o estudioso do Direito a alocação de recursos normalmente (mas não exclusivamente) envolve uma colisão a ser solvida através da ponderação dos princípios envolvidos, para o agente político envolve uma opção (GALDINO, 2005, p. 158). Essa opção acaba por espelhar valores que, embora circunstanciais, existem e estão no seio da sociedade. "Isso porque as decisões (ou escolhas) acerca das alocações dos recursos para tutela de determinados direitos, enquanto outros restarão desprotegidos, espelha os valores da sociedade em questão" (GALDINO, 2005, p. 221).

$\mathrm{Na}$ verdade, a realização de direitos impõe estratégias sociais prospectivas, complexas, mutantes como a realidade na qual os direitos devem ser realizados. No mais das vezes, é imprescindível a análise sistêmica e não individualizada dos direitos, pois, como visto, no plano da escassez, a alocação justa de direitos deve colocar na balança as trágicas escolhas possíveis e não apenas as (eventualmente pródigas) opções axiológicas do legislador eventual ou do administrador da hora (GALDINO, 2005, p. 343). 


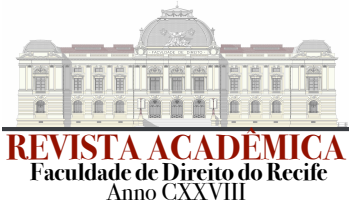

No caso das escolhas que envolvem um maior/melhor investimento no poder judiciário, a fim de possibilitar um acesso à justiça mais adequado, é preciso entender não só toda a complexidade do sistema jurídico brasileiro, mas também em saber o quanto estamos dispostos a pagar para melhorá-lo.

Foi demonstrado na seção 3.2 deste trabalho que o Brasil investe no Poder Judiciário dez vezes mais em relação ao seu PIB do que a Argentina, cerca de nove vezes mais do que o Estados Unidos e a Inglaterra. No entanto, foi visto também que ele é muito mais demandado do que as cortes desses países. Isso significa que, havendo uma desproporção nas necessidades do sistema, é natural que haja também uma desproporção de investimentos. Não faz sentido se exigir que o país " $\mathrm{A}$ " invista o mesmo que o país " $B$ " no enfrentamento da doença "X", se em "A" existe uma epidemia de "X" e em "B" a doença existe, mas está sob controle.

Dessa forma, tais investimentos precisam ser levados em consideração em um cenário de escassez de recurso, no qual "o debate sobre o tipo de país que o Brasil quer ser crescentemente deverá levar em conta também o tamanho da comunidade jurídica que a sua população pode e/ou deseja sustentar" (ROS, 2015a, p. 09).

Por isso, um dos caminhos acerca do quanto deve ser investido deverá passar por questões de políticas orçamentárias. Tema este que será tratado a seguir.

\subsection{DAS ESCOLHAS ORÇAMENTÁRIAS}

A importância das questões orçamentárias para a concretização de direitos vem sendo refletida também no próprio conceito de orçamento. A lei orçamentária na modernidade, por exemplo, "deixa de ser mero documento financeiro ou contábil para passar a ser o instrumento de ação do Estado. Através dele é que se fixam os objetivos a serem atingidos" (OLIVEIRA, 2010, p. 343).

Assim sendo, “o orçamento não pode ser mera peça financeira, nem apenas simples plano de governo, mas representa o compromisso político de cumprimento de promessas sérias levadas ao povo. A previsão desperta esperança, expectativa de satisfação dos compromissos, certeza de que os desejos serão atendidos" (OLIVEIRA, 2010, p. 350). 


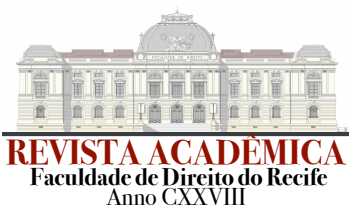

Luiz Roberto Barroso (2009, p. 05), em audiência pública realizada no Supremo Tribunal Federal, quando se discutia a judicialização da saúde, chamou a atenção para a cultura de não se discutir as questões orçamentária no Brasil. Em suas palavras, "todas as sociedades democráticas debatem: quanto vai para educação, quanto vai para a construção de estradas[....]. E nós temos que estabelecer o quanto vai para a saúde e procurar determinar qual é o justo em saúde naquele momento e naquele determinado lugar”.

O mesmo paralelo que é apresentado pelo Autor para o caso da saúde, pode ser feito no caso do acesso à justiça. Conforme explicado por Holmes e Suntein (1999, p. 45) nenhum sistema judicial pode operar em um vazio orçamentário.

Nenhum tribunal pode funcionar sem receber injeções regulares de dinheiro dos contribuintes para financiar seus esforços para sancionar aqueles que violam direitos públicos ou privados e, quando essas quantias não estão disponíveis, os direitos não podem ser adequadamente reivindicados. $\mathrm{Na}$ medida em que os direitos exigidos dependem da vigilância judicial, os direitos custam, no mínimo, o que seja necessário para recrutar, treinar, fornecer e pagar aqueles que resguardam judicialmente nossos direitos básicos (HOLMES; SUNSTEIN, 1999, p. 45, tradução nossa).

Talvez, o que se deveria discutir mais no Brasil - e é um dos propósitos deste trabalho, trazer tal discussão - é quanto deve ser gasto para a manutenção do Poder Judiciário em determinado momento e em determinado lugar. Assim é importante perceber, pois "dar aos cidadãos o acesso aos tribunais não é como dar-lhes acesso a portos naturais e águas navegáveis, porque o governo não só deve evitar os obstáculos ao acesso, mas deve criar, também, as instituições às quais o acesso deve ser concedido" (HOLMES; SUNSTEIN, 1999, p. 54, tradução nossa).

Ora, se a quantidade de demandas no Brasil cresce, é preciso, prima facie, que cresçam também os recursos para a resolução desse problema, ou que ao menos se discuta como melhor gastar o dinheiro já alocado. Não é porque, comparado a outros países, o Brasil já tem um gasto elevado com relação ao PIB, que necessariamente isso significa que se tenha que gastar menos. Mas talvez indique que se precisa gastar melhor.

Um dos problemas dessa situação é que "há no Brasil um vazio, que é o debate público sobre a elaboração do orçamento. Há um momento na vida democrática de todos os Estados no qual se tomam as decisões e se fazem as escolhas - as boas e as trágicas - e esta discussão é negligenciada no Brasil” (BARROSO, 2009, p. 03-04). 


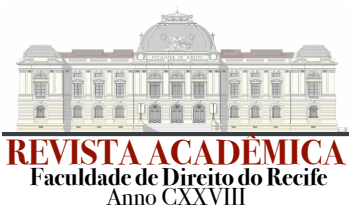

O momento da elaboração dos orçamentos é o espaço do grande debate público sobre as políticas a serem realizadas em prol do país. Essas decisões, em razão de seu caráter disjuntivo, "caberia ao povo tomá-las, diretamente ou por meio de seus representantes eleitos" (BARROSO, 2009, p. 24).

Por isso, "a importância do Direito Financeiro se mostra presente e cresce a cada dia ao ficarem claras as tensões decorrentes da falta de recursos para atender as necessidades públicas e assegurar os direitos previstos em nossa Constituição" (CONTI, 2016, p. 06). Dessa maneira, é importante levar o olhar para esse que é de um dos problemas do acesso à justiça: a disponibilidade de orçamento para criar e manter uma estrutura adequada para a demanda do país.

Esse reconhecimento, da importância da discussão do orçamento, pouco a pouco vem ganhando mais fôlego no Brasil, a ponto de já haver manifestação do STF no sentido de que a Lei orçamentária, materialmente falando, seria a lei mais importante do Estado brasileiro, abaixo apenas da Constituição Federal ${ }^{2}$. No entanto, tal visão, aparentemente, ainda não foi assimilada nem pela população, nem pelos próprios legisladores e membros do executivo federal, o que revela, por exemplo, como quando ocorreu em 2014 e 2015, quando os exercícios financeiros dos referidos anos começaram sem sequer ter havido a aprovação de seus respectivos orçamentos.

Dessa maneira, é necessário reconhecer que há espaço para a discussão orçamentária, que deve ser levada em consideração quando se aborda sobre a efetividade de direitos, quaisquer que sejam, principalmente, aqueles que demandam uma dependência maior do aparelhamento estatal. Afinal, é "o orçamento, como lei, que define os recursos à disposição do Poder Público para atender às demandas e estabelece onde e como serão gastos" (CONTI, 2016, p. 06).

Conforme sustentado por Holmes e Suntein (1999, p. 98, tradução nossa), "as finanças públicas são uma ciência ética porque nos obriga a fornecer uma contabilidade pública para os

2 Ministro Ayres de Brito, em julgamento da ADI 4.048-MC / DF, disse: "E nova ordem jurídica, primariamente, no sentido de, logo abaixo da Constituição, quem inova a ordem jurídica é a lei. E, no caso da lei orçamentária - Vossa Excelência disse muito bem -, no fundo, abaixo da Constituição, não há lei mais importante para o país, porque a que mais influencia o destino da coletividade, do que esta lei. A lei orçamentária é a lei materialmente mais importante do ordenamento jurídico logo abaixo da Constituição. E deixar essa lei do lado de fora do controle de constitucionalidade, em processos objetivos, parece um contrassenso realmente" (BRASIL, 2008, p. 38). 


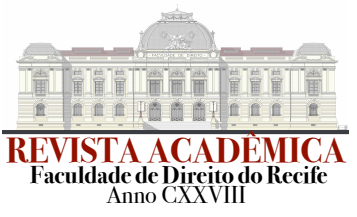

sacrifícios que nós, como comunidade, decidimos fazer, para explicar o que estamos dispostos a abandonar na busca de nossos objetivos mais importantes".

Por isso, as discussões acerca do acesso à justiça, das despesas com o judiciário e da salvaguarda de direitos pode evidenciar ganhos significativos quando iluminadas com base nas escolhas orçamentárias de decisão política, de maneira que a sociedade possa passar a tomar consciência de que cada direito que escolhemos proteger, até determinado ponto, implica na não-proteção de outro. E, assim, devemos estar preparados para fazer tais escolhas e arcar com as consequências delas.

\section{CONSIDERAÇÕES FINAIS}

O acesso à justiça é um direito fundamental para o funcionamento de todo o Estado. Está diretamente vinculado com sua capacidade em realizar uma de suas mais básicas funções: resolver os litígios existentes no meio social. Por isso, o desejo pretenso em aumentar a acessibilidade dos cidadãos ao Poder Judiciário e ter dele uma boa qualidade de serviço é um justo desígnio, mas que encontra limites de realização material-estrutural vinculado às questões orçamentárias e merece a atenção adequada dos estudiosos do tema.

Pode-se perceber que, no decorrer histórico do acesso à justiça no Brasil, houve um nítido esforço legislativo em provocar mudanças para tratar de forma mais adequada o acesso à justiça, criando leis que diminuem ou isentam os custos judiciais, organizam demandas coletivas, estruturando-se a Defensoria Pública e ampliando-se os poderes e prerrogativas do Ministério Público, por exemplo. No entanto, o Estado brasileiro não conseguiu equipar suficientemente o Poder Judiciário para as demandas reprimidas e que surgiram com o aumento do acesso à justiça por meio do judiciário.

Por isso, a ideia de que toda proteção a determinado direito tem um custo, se mostrou como uma valiosa ferramenta para situar o problema do acesso à justiça perante outros direitos constitucionais. A análise dos custos do Poder Judiciário e sua participação nas despesas públicas possibilitaram a verificação, em um estudo comparado, de que não há um descaso orçamentário para o custeio do poder Judiciário, mas uma excessiva demanda em 


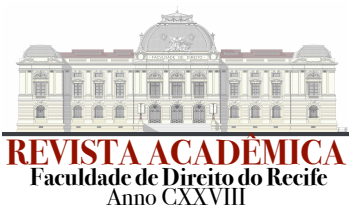

razão da necessidade de judicialização de diversas relações jurídicas que, por serem precárias, acabam alcançando o judiciário em busca de uma solução.

Isso tudo fez levar o problema ao início do processo deliberativo, em que o acesso à justiça é colocado lado a lado com outros direitos fundamentais, e, por ter um custo orçamentário, disputa com os demais direitos uma fatia do orçamento público. Assim, as escolhas disjuntivas orçamentárias, no âmbito das escolhas políticas, fornecem um palco mais adequado para a disposição dos gastos públicos em que o povo, ou seus representantes, podem distribuir, conforme as suas preferências, como deve ser gasto o dinheiro recolhido pelo Estado.

Dessa forma, foi possível fazer o enlace proposto no trabalho entre a teoria do acesso à justiça e a teoria dos custos do direito, mostrando que é preciso fortalecer os aspectos participativos no Direito Financeiro, a fim de tornar mais consciente o que se escolhe e o que se abre mão em razão dessas escolhas orçamentárias, assumindo-se, assim, as consequências, sejam elas positivas ou negativas, das opções deliberativas.

\section{REFERÊNCIAS}

AMARAL, Gustavo. Direito, escassez e escolha: em busca de critérios jurídicos para lidar com a escassez de recursos e as decisões trágicas. Rio de Janeiro: Renovar, 2001

BARROSO, Luís Roberto. Ata de audiência pública n. 04, do Supremo Tribunal Federal, 2009. Disponível em <http://www.stf.jus.br/arquivo/cms/processoAudienciaPublicaSaude/ anexo/Luis_Roberto_Barroso.pdf $>$. Acesso em 12 ago 2017.

BEZERRA, Paulo Cesar Santos. Acesso à justiça: um problema ético-social no plano da realização do direito. Rio de Janeiro: Renovar, 2008.

BRASIL. Conselho Nacional de Justiça. Justiça em números 2017: ano-base 2016. Brasília: CNJ, 2017a. Disponível em: <http://www.cnj.jus.br/files/conteudo/arquivo/2017/09/ ccbf89236e608e0c2bc755bee863b68a.pdf>. Acesso em 05 set 2017.

Constituição (1988). Constituição da República Federativa do Brasil. Disponível $\overline{\mathrm{em}<\mathrm{http}}$ ://www.planalto.gov.br/ccivil_03/constituicao/constituição.htm>. Acesso em 20 jul 2017. 


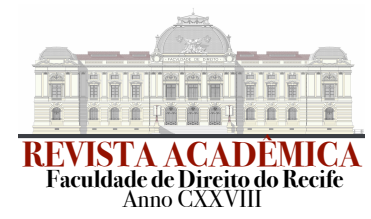

Constituição (1824). Constituição Política do Império do Brasil. Disponível em $<$ http://www.planalto.gov.br/ccivil_03/constituicao/constituicao46.htm>. Acesso em 20 jul 2017.

Constituição (1946). Constituição dos Estados Unidos do Brasil. Disponível em <http://www.planalto.gov.br/ccivil_03/constituicao/constituição.htm>. Acesso em 20 jul 2017.

Instituto Brasileiro de Geografia e Estatísticas. Projeção da população do Brasil e das unidades da Federação. 2017b. Disponível em: <http://www.ibge.gov.br/apps/ populacao/projecao/> Acesso em 26 jul 2017.

IPEADATA. Série histórica do PIB no Brasil. 2017c. Disponível em: <http:// www.ipeadata.gov.br/Default.aspx>. Acesso em 29 jul 2017.

SUPREMO TRIBUNAL FEDERAL. ADI 4.048-1-MC/DF, Relator Min. Gilmar Mendes em 14 de maio de 2008. Órgão julgador: Tribunal Pleno. Publicado em diário da justiça de 22 de agosto de 2008. Ementário: vol.02329-01 (2008).

Decreto $N^{\mathbf{0}}$. 678/92. Promulga a Convenção Interamericana sobre Direitos Humanos de 22 de novembro de 1969. Brasília: Presidência da República, 1992.

CAPPELlETTI, Mauro; GARTH, Bryant. Acesso à Justiça. Porto Alegre: Sergio Antonio Fabris Editor, 1988.

CONTI, José Maurício. Levando o Direito Financeiro a sério. São Paulo: Blucher, 2016.

ROS, Luciano da. 2015a. O custo da Justiça no Brasil: uma análise comparativa exploratória. Newsletter. Observatório de elites políticas e sociais do Brasil. NUSP/UFPR, v.2, n. 9, julho. p. 1-15. Disponível em: <http://observatory-elites.org/wp-content/uploads/2012/06/ newsletter-Observatorio-v.-2-n.-9.pdf>. Acesso em 31 jul 2017.

Na relação com o PIB, Judiciário brasileiro custa quatro vezes o registrado na Alemanha. O Globo. 11 ago 2015b. Entrevista concedida a Fábio Vasconcellos. Disponível em <http://blogs.oglobo.globo.com/na-base-dos-dados/post/custo-relativo-ao-pib-dojudiciario-brasileiro-e-quatro-vezes-o-registrado-na-alemanha.html>. Acesso em 31 jul 2017.

GALDINO, Flávio. Introdução à teoria dos custos dos direitos: Direitos não nascem em árvores. Rio de Janeiro: Lumen Juris, 2005.

HOLMES, Stephen; SUNSTEIN, Cass. The Cost of Rights: Why liberty depends on taxes, New York and London: W. M. Norton, 1999.

MACHADO, Clara Cardoso. Direitos fundamentais sociais, custos e escolhas orçamentárias: em busca de parâmetros constitucionais. In: Âmbito Jurídico, Rio Grande, XIII, n. 82, nov. 


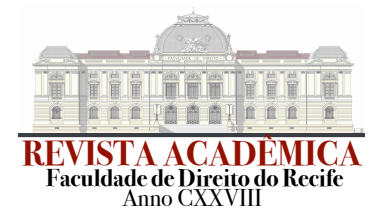

2010. Disponível em: <http://www.ambitojuridico.com.br/site/index.php? $\mathrm{n}$ _link=revista_artigos_leitura\&artigo_id=8571>. Acesso em 10 jun 2017.

OLIVEIRA, Regis Fernandes de. Curso de Direito Financeiro. 3. ed. rev. atual. São Paulo: Revista dos Tribunais, 2010.

SANTOS, Boaventura de Sousa. Notas sobre a história jurídico social de Pasárgada, 1999. Disponível em: <http://derecho.posgrado.unam.mx/congresos/cursoboaventura/ boavpassar.pdf $>$. Acesso em 13 mai 2017.

. Para uma revolução democrática da justiça. São Paulo: Cortez, 2007.

SADEK, Maria Tereza Aina. Acesso à justiça: porta de entrada para a inclusão social. In LIVIANU, R., cood. Justiça, cidadania e democracia [online]. Rio de Janeiro: Centro Edelstein de Pesquisa Social, 2009. pp. 170-180. Disponível em: <http://books.scielo.org/id/ ff2x7/pdf/livianu-9788579820137-15.pdf $>$. Acesso em 20 jun 2017.

Judiciário: mudanças e reformas. Estud. av., São Paulo , v. 18, n. 51, Aug. 2004. Disponível em < http://www.scielo.br/pdf/ea/v18n51/a05v1851.pdf >. Acesso em 25 mai 2017.

. Acesso à justiça: um direito e seus obstáculos. REVISTA USP, São Paulo, n. 101, março/abril/maio. 2014. Disponível em: <http://www.journals.usp.br/revusp/article/view/ 87814/90736>. Acesso em 23 jul 2017.

(org.). O sistema de justiça. Rio de Janeiro: Centro Edelstein de Pesquisas Sociais, 2010. O sistema de justiça. pp. 1-23. ISBN: 978-85-7982-039-7. Disponível em $<\mathrm{http}: / /$ books.scielo.org/id/59fv5/pdf/sadek-9788579820397-01.pdf>. Acesso em 15 jun 2017.

(org,). O judiciário em debate. Rio de Janeiro: Centro Edelstein de Pesquisas Sociais, 2010. Disponível em <http://static.scielo.org/scielobooks/82r9t/pdf/ sadek-9788579820342.pdf>. Acesso em 15 jun 2017.

SARMENTO, Daniel. Dignidade da Pessoa humana: conteúdo, trajetórias e metodologia. Belo Horizonte: Fórum, 2016.

SOUZA, Michel Faria de. A história do acesso à Justiça no Brasil. In: Âmbito Jurídico, Rio Grande, XIX, n. 149, jun 2016. Disponível em: <http://ambitojuridico.com.br/site/? n_link=revista_artigos_leitura\&artigo_id=17348>. Acesso em 12 jul 2017.

SOUZA, Wilson Alves de. Acesso à justiça: conceito, problemas e a busca da sua superação. Evocati. Revista $\mathrm{n}^{\mathrm{o}}$ 42, 30 de jun de 2009. Disponível em: <http://www.evocati.com.br/ evocati/artigos.wsp?tmp_codartigo=332>. Acesso em 10 jun 2017.

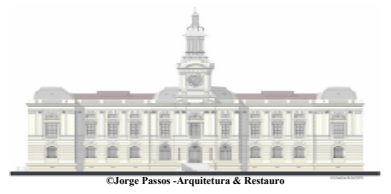

